\title{
Risks for Child Cognitive Development in Rural Contexts
}

\author{
Maria Julia Hermida ${ }^{1,2,3 *}$, Diego Edgar Shalom ${ }^{4,5}$, María Soledad Segretin ${ }^{4,6}$, \\ Andrea Paula Goldin 1,4, Marcelo Claudio Abril2, Sebastián Javier Lipina ${ }^{4,6}$ and \\ Mariano Sigman ${ }^{1,4,7}$
}

\begin{abstract}
${ }^{1}$ Laboratorio de Neurociencia, Universidad Torcuato Di Tella, Buenos Aires, Argentina, ${ }^{2}$ Fundación Mundo Sano, Buenos Aires, Argentina, ${ }^{3}$ Instituto de Educación, Universidad Nacional de Hurlingham, Buenos Aires, Argentina, ${ }^{4}$ Consejo Nacional de Investigaciones Cientificas y Técnicas, Buenos Aires, Argentina, ${ }^{5}$ Departamento de Física, Facultad de Ciencias Exactas y Naturales, Universidad de Buenos Aires, Buenos Aires, Argentina, ${ }^{6}$ Unidad de Neurobiología Aplicada, Centro de Educación Médica e Investigaciones Clínicas "Norberto Quirno", Buenos Aires, Argentina, ${ }^{7}$ Facultad de Lenguas y Educación, Universidad Nebrija, Madrid, Spain
\end{abstract}

\section{OPEN ACCESS}

Edited by:

Yvette Renee Harris,

Miami University, United States

Reviewed by: Carolyn Palmquist,

Amherst College, United States Alejandro Maiche,

Universidad de la República, Uruguay

*Correspondence:

Maria Julia Hermida

julia.hermida@gmail.com

Specialty section:

This article was submitted to Developmental Psychology, a section of the journal

Frontiers in Psychology

Received: 23 July 2018 Accepted: 19 December 2018

Published: 09 January 2019

Citation:

Hermida MJ, Shalom DE Segretin MS, Goldin AP, Abril MC Lipina SJ and Sigman M (2019) Risks for Child Cognitive Development in Rural Contexts.

Front. Psychol. 9:2735. doi: 10.3389/fpsyg.2018.02735
While poverty all over the world is more typical and extreme in rural contexts, interventions to improve cognition in low socioeconomic status (SES) children are for the most part based on studies conducted in urban populations. This paper investigate how poverty and rural or urban settings affect child cognitive performance. Executive functions and non-verbal intelligence performance, as well as individual and environmental information was obtained from 1315 -year-old children. For the same level of SES, children in rural settings performed consistently worse than children in urban settings. These differences could be accounted mostly by the months of past preschool attendance and the father's completed level of education. These results should inform policies and programs for children living in rural poverty worldwide, and specially in Latin America.

Keywords: socioeconomic status, rural context, urban context, child cognitive development, executive functions, preschool attendance, father's educational level

\section{INTRODUCTION}

Over the last few years, substantial effort has been committed to design public policies and interventions to attenuate the negative effect of poverty in child cognitive development (Bradley and Corwyn, 2002, p. 372; Slavin, 2002, p. 15; Bierman et al., 2008, p. 1810; Yoshikawa et al., 2012, p. 272; Richter et al., 2017, p. 103). While this scientific program is in Stoke's "Pasteur Quadrant" (Stokes, 2011, pp. 1-196; Sigman et al., 2014, p. 497) of basic research inspired by use and practical applications, there is an incongruity: although worldwide the incidence of extreme poverty is much more prominent in rural contexts, most of studies on the effects of poverty in cognitive development have been carried out in urban populations (Lichter and Johnson, 2007, p. 331; Schreuder, 2010, p. 45; Tine, 2017, pp. 9-22). For example, in Argentina the incidence of non-urban, poverty is $18.2 \%$ while the incidence of urban poverty is $8.3 \%$ (Instituto Nacional de Estadísticas y Censos, 2010, p. 217). Importantly, most of the inhabitants living in extreme poverty are children (Olinto et al., 2013, p. 125).

In fact, the effects of poverty and the effects of living in a non-urban context are often confounded in scientific studies, because low SES is most prevalent in rural samples (Foulkes et al., 2008, p. 129; Morgan, 2015, p. 1). Some studies have analyzed developmental or academic trajectories in rural low SES children, without including comparisons with urban peers 
(Brody et al., 2002, p. 1505; Nadel and Sagawa, 2002, pp. 1-105; Vernon-Feagans and Cox, 2013, pp. 1-23). A second group of studies (Förster and Rojas-Barahona, 2014, pp. 346504; Mykerezi et al., 2014, p. 17; Castro and Rolleston, 2015, pp. 5-48) examined the rural-urban gap in cognition, but only atone SES level (i.e., low-SES children). A third group of studies has identified effects of poverty and effects of context, but do not separate those effects (Foulkes et al., 2008, p. 129; Foulkes and Mori, 2009; Gouin et al., 2015). A fourth group of studies, go deeper in the associations among poverty, context and cognition, examining whether the form and magnitude of income's relationship with early reading and math achievement differ across the urban-rural continuum (Miller and Votruba-Drzal, 2013, p. 234; Miller et al., 2013, p. 1452). However, those studies were not focalized in separating the effects of poverty and context. In addition, none of those studies analyzed cognition in terms of executive functions. There is just one study that analyzed executive functions in rural low SES samples (Vernon-Feagans and Cox, 2013, pp. 1-23), but it also does not compare achievements with an urban sample. In conclusion, although some studies have investigated cognitive development in rural contexts, they were not designed to factor out the effect of poverty from the effect of living in urban or rural context in executive functions.

More generally, while the terms poverty and low SES has been used broadly to refer to scarceness and generally associated to risks of cognitive development, to design evidence based policies and interventions, it is imperative to determine what components of low SES, and their interactions, present a major risk for cognitive development (Lipina, 2016, p. 241; Duncan et al., 2017, p. 413).

A review of the existing literature suggests that several aspects of scarceness which are prevalent in rural contexts may present high risk factors for cognitive development. For example: lack of access to social services, public health, and resources (Foulkes and Mori, 2009, p. 83; Miller and Votruba-Drzal, 2013, p. 234; Gouin et al., 2015, p. 10; Morgan, 2015, p. 1; Robinson, 2017, pp. 1-11), lower quality of education, teachers with lower wages and levels of training, reduced access to preschool education (Castro and Rolleston, 2015, pp. 5-48; Gouin et al., 2015, p. 10), fewer years of parental education (Nadel and Sagawa, 2002, p. 61; Foulkes et al., 2008, p. 129; Foulkes and Mori, 2009, p. 83; Mykerezi et al., 2014, p. 17; Tine, 2017, p. 9), and significantly less familiar stimulation at home (Burchinal et al., 2008, p. 41; Miller and Votruba-Drzal, 2013, p. 234; Förster and Rojas-Barahona, 2014, p. 476). Though this picture seems grim, some studies have found a positive association between living in a rural context and academic achievement (i.e., language, verbal memory, and school adaptation) (Paxson and Schady, 2007, p. 49; Miller et al., 2013, p. 1452; Tine, 2014, p. 599), and it has been suggested that exposure to nearby nature may be a buffer for everyday life stress in children (Wells and Evans, 2003, p. 311). Hence, there are contradictory views and results regarding the impact of living in a rural context on cognitive development. A meta-analysis of these studies is very difficult because they have used different criteria to define rurality (Hart et al., 2005, p. 1149).
There is an additional challenge to compare those results: the variability in the cognitive measures used across studies. Amongst the cognitive variables often measured throughout development, Executive Functions (EF) have been established as good predictors of the child's self-regulatory abilities, and their future academic performance and well-being (McClelland, 1973, pp. 1-14; Brooks-Gunn and Duncan, 1997, p. 55; Blair and Diamond, 2008, p. 899; Moffitt et al., 2011, p. 2693). However, research in rural contexts have mostly focused in other variables such as non-verbal intelligence (Berry et al., 2016, p. 115).

The central aim of this study is to compare cognitive achievement in selected samples from different SES and contexts to understand which aspects of rural poverty pose the main risks to cognitive development. The overarching goal of our research program is to contribute showing critical information to the design of public policies and education programs that can be tailored to the specific needs of different contexts and SES groups.

\section{MATERIALS AND METHODS}

\section{Design and Participants}

We applied a cross-sectional design, with purposive sampling. Selected samples from different SES and contexts (rural/urban) were evaluated with cognitive tasks as well as individual and environmental variables. The minimum sample size required was calculated considering an anticipated effect size of 0.15 , a statistical power level of 0.8 , two predictors (context and UBN), and a probability level of 0.05 (Cohen et al., 2013). One hundred and thirty one 5-year-olds (68 males; mean age in years $=5.36$, $S D=0.27$ ) recruited in four public schools and their families participated in the study Table 1 . Two of the schools were urban, located in the City of Buenos Aires, which has 2890151 habitants (Olinto et al., 2013, pp. 1-8) and is the city with the highest percentage of urban population in Argentina.

The other two schools were located in Santiago del Estero, the province of that has the highest percentage of rural population in Argentina (31.3\% of Santiago del Estero's population is rural). Specifically, schools were in Añatuya's outskirts, a city with 23286 habitants and an average density population of 6.3 habitants $/ \mathrm{km} 2$. Based on Miller and Votruba-Drzal (2013, p. 234) 'rural' criteria (an area with population less than 50000 inhabitants which is independent of a metropolis -less than $30 \%$ of the population go to work to a metropolis-), both schools were considered rural.

All children attended the school on either the morning or afternoon shifts. The number of children on each shift did not differ by living context $(U=1685, Z=1.736, p=0.082$ ). In addition, rural and urban children did not differ significantly by

TABLE 1 | Frequencies by socioeconomic level and context.

\begin{tabular}{lcc}
\hline Number of UBN indicators & Rural & Urban \\
\hline 0 & 8 & 61 \\
1 & 15 & 14 \\
2 & 25 & 8 \\
& 48 & 83
\end{tabular}


gender $\left(\chi^{2}=1.636, \mathrm{df}=3, p=0.651\right)$ or age $\left[F_{(1,126)}=0.214\right.$; $p=0.887]$. All the schools provided children with a meal and a snack. Primary caregivers gave written informed consent to participate in the study, which was authorized by an institutional Ethical Committee (Centro de Educación Médica e Investigaciones Clínicas, Consejo Nacional de Investigaciones Científicas y Técnicas, Protocol N 967). The study was conducted in accordance with APA's ethical standards, and international and national children rights laws.

\section{EF and Non-verbal Intelligence Assessment}

\section{Attention}

To assess Attention, we used the Attention subtest of CUMANIN Battery (Children Neuropsychological Maturity Questionnaire) (Portellano et al., 2000, pp. 1-28), a cancelation task in which the child is given $30 \mathrm{~s}$ to identify and strike out the 20 geometric figures that are equal to a target (square) in a copy containing 100 figures.

\section{Inhibitory Control}

Day and Night like-Stroop test (Gerstadt et al., 1994, p. 129), in Tardif and collaborators variant (Tardif et al., 2007, p. 318), was applied to assess Inhibitory control. Children were presented a congruent block of 10 trials (where the child should say 'day' when seeing the sun card), followed by an incongruent block of 10 trials (where the child should say 'night' when seeing the picture of the sun).

\section{Working Memory}

Forward digit span subtest of WISC III (Wechsler Intelligence Scale for Children III) (Wechsler, 1991, p. 219) was used to evaluate Working memory. In this task, the child must repeat number sequences in the same order they were listened.

\section{Flexibility}

Dimensional Change Card Sort (DCCS) (Frye et al., 1995), in the standard version (Zelazo, 2006, p. 297) was used to assess Flexibility. This is a game of two dimensions cards that children should classify according to a first dimension (color) and then another dimension (shape). The outcome variable of this task was ordinal. Therefore, with this variable, we applied ordinal regressions.

\section{Non-verbal Intelligence}

The Test of Non-verbal Intelligence 4 (TONI-4) (Brown et al., 2010 , p. 1) was applied to evaluate Non-verbal intelligence (Horn and Cattell, 1966, p. 253). Each item consists of a sequence of abstract figures in which the child must select the only option that complete the pattern.

\section{Learning}

The Subtest Coding of WPPSI III battery (Intelligence Scale Wechsler Preschool and Primary III) was implemented to assessed Learning ability (Wechsler, 2004, pp. 1-329). The child must copy a series of symbols within geometric shapes, during $2 \mathrm{~min}$. Each symbol is paired with a geometric shape and the child has a model that reminds correspondences.
All tests were presented in the listed order. We considered as general Non-verbal intelligence measures only TONI4 (Intelligence) and Coding (Learning) tasks. All the other tests were EF measures. The inclusion of EF and Non-verbal intelligence measures was aimed at obtaining a whole cognitive assessment, complementing data of general measures with data from basic executive processes tests.

\section{Evaluation of Individual and Environmental Variables}

To obtain individual and environmental information of children, we performed interviews with parents or caregivers. Scales were administered in the following order:

\section{Environmental Variables}

The Socioeconomic Level Scale (NES) (Colombo and Lipina, 2005, pp. 1-173) was used to estimate: (1) the presence and number of indicators of Unsatisfied Basic Needs (UBN indicators) at home; (2) health history of the child; (3) home stimulation; and (4) demographic variables (e.g., age, gender, time of residence in the place).

\section{Child Temperament}

The very short form of the Child Behavioral Questionnaire (Putnam and Rothbart, 2006, p. 102) for children 3-7 years was administered to evaluate child temperament. The behavior of children is evaluated by their mothers following an 8-point scale according to how true is each behavior in the case of his son.

\section{Mother Mental Health}

The Hamilton Anxiety and Depression Scale (Hamilton, 1960, p. 56) which consists of 14 items related to signs and symptoms of anxiety and depression, and value the intensity and frequency of such behaviors during 20 days prior to the interview was used to obtain mother mental health indicators.

From all those three scales, we obtained 35 individual and environmental variables (list of variables in Tables 2, 3).

\section{SES Assessment: Number of Unsatisfied Basic Needs Indicators}

From the information obtained through the NES Scale we applied the UBN approach in order to have a chronic poverty measure. Following the national poverty criteria (Instituto Nacional de Estadísticas y Censos, 2010, p. 52) we considered an UBN home the one that has at least one of these indicators: (1) Subsistence capacity (UBN 1): head of household with incomplete primary school educational level, and more than four dependents. (2) School truancy (UBN 2): presence of school-aged children (615 years-old) who do not attend any educational system. (3) Inappropriate dwelling (UBN 3): the house is a hotel or pension, poor housing or other housing not built for residential purposes. (4) Sanitary deficiencies (UBN 4): home with no flush toilet. (5) Overcrowding (UBN 5): home in which the ratio of the total number of home members to the number of rooms used to sleep is equal or higher than 3 . In a second step, we counted the number of UBN indicators in order to distinguish levels of SES. Within 
TABLE 2 | Descriptive statistic of the continuous variables obtained from parents' interviews in urban and rural contexts.

\begin{tabular}{|c|c|c|c|c|c|c|}
\hline \multirow[b]{2}{*}{ Continuous variables } & \multicolumn{3}{|c|}{ Urban } & \multicolumn{3}{|c|}{ Rural } \\
\hline & $n$ & Mean & $S D$ & $n$ & Mean & $S D$ \\
\hline Time of residence in the place & 83 & 4.88 & 2.28 & 48 & 5.88 & 0.61 \\
\hline Number of siblings ${ }^{1}$ & 83 & 1.34 & 0.99 & 47 & 2.53 & 1.36 \\
\hline Birth order ${ }^{2}$ & 82 & 1.76 & 0.90 & 47 & 2.62 & 1.21 \\
\hline Health history & 77 & 0.91 & 1.04 & 47 & 1.19 & 1.14 \\
\hline Pregnancy health history & 77 & 0.21 & 0.41 & 45 & 0.27 & 0.45 \\
\hline Father's age & 73 & 35.93 & 7.38 & 43 & 32.60 & 7.23 \\
\hline Mother's age & 76 & 32.89 & 6.93 & 48 & 29.21 & 7.15 \\
\hline Number of dependents in the household ${ }^{3}$ & 82 & 3.74 & 1.40 & 47 & 5.02 & 1.66 \\
\hline Father's completed level of education ${ }^{4}$ & 72 & 7.39 & 2.84 & 41 & 2.41 & 1.72 \\
\hline Mother's completed level of education & 79 & 7.22 & 3.30 & 43 & 2.93 & 2.31 \\
\hline Father's occupation ${ }^{5}$ & 78 & 3.73 & 1.79 & 45 & 1.51 & 1.01 \\
\hline Mother's occupation score & 81 & 2.16 & 2.44 & 46 & 0.33 & 0.97 \\
\hline Number of government subsidies ${ }^{6}$ & 77 & 0.51 & 0.62 & 47 & 1.02 & 0.49 \\
\hline Dwelling score & 77 & 11.26 & 1.47 & 47 & 8.62 & 2.13 \\
\hline Past preschool attendance ${ }^{7}$ & 77 & 21.97 & 9.62 & 47 & 7.91 & 5.75 \\
\hline Number of books at home & 77 & 1.95 & 1.00 & 47 & 2.81 & 0.54 \\
\hline Frequency of mother-child play (by week) & 76 & 5.14 & 2.40 & 47 & 4.62 & 2.85 \\
\hline Frequency of reading newspapers (by week) & 67 & 2.49 & 2.28 & 46 & 3.83 & 2.69 \\
\hline Frequency of watching TV (by week) & 73 & 5.66 & 2.14 & 47 & 4.83 & 3.04 \\
\hline Frequency of listening to the radio (by week) & 71 & 1.92 & 2.83 & 47 & 4.30 & 3.34 \\
\hline Frequency of using computers (by week) & 71 & 2.83 & 3.03 & 47 & 0.36 & 1.48 \\
\hline Frequency of using cellphone (by week) & 66 & 1.74 & 2.61 & 47 & 2.62 & 3.19 \\
\hline Mother anxiety & 67 & 8.91 & 3.54 & 37 & 9.08 & 3.93 \\
\hline Mother depression & 67 & 5.46 & 4.10 & 37 & 5.62 & 4.04 \\
\hline Surgency & 76 & 4.39 & 0.82 & 45 & 4.27 & 0.89 \\
\hline Negative affect & 76 & 4.60 & 0.79 & 45 & 4.37 & 0.85 \\
\hline Effortful control & 76 & 5.76 & 0.68 & 45 & 5.43 & 0.73 \\
\hline Age & 83 & 5.35 & 0.28 & 43 & 5.38 & 0.26 \\
\hline
\end{tabular}

${ }^{1}$ Total number of siblings of the child.

${ }^{2}$ Order in which the child was born.

${ }^{3}$ Number of people that economically depends on the household.

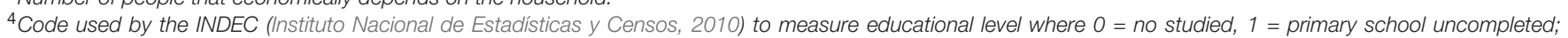

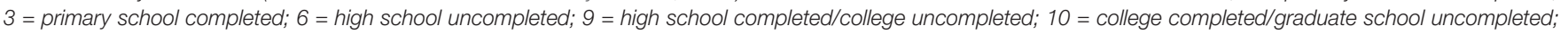

12 = graduate school completed.

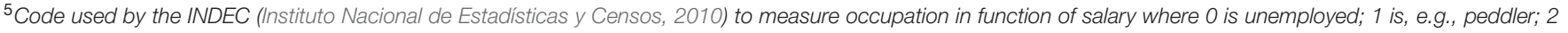
is. e.g., a street sweeper; 4 is, e.g., taxi driver; etc.

${ }^{6}$ Number of subsidies given by the government to that family.

${ }^{7}$ Amount of months that the child had attended school before the year of the study.

UBN homes, we can differentiate between those which have one (lower poverty level) and those that have two or more UBN indicators (higher poverty level).

\section{Evaluation of Context: Rural/Urban}

Based on Miller and Votruba-Drzal (2013, p. 234) we considered as 'rural' an area with population less than 50000 inhabitants which is independent of a metropolis (less than $30 \%$ of the population go to work to a metropolis). All homes of children evaluated in the city of Añatuya meet the criteria to be considered rural. Similarly, we define urban as a city with a population higher than 150000. All homes of children evaluated in the Autonomous City of Buenos Aires meet that criterion.

\section{Statistical Analysis}

Data is available in a repository (Hermida, 2018). Data from children with diagnosed developmental disabilities or neurological diseases were excluded from the study.

We conducted all analysis for each cognitive process separately in order to detect function-specific susceptibilities to environmental conditions at this time of development.

In the first step, to determine the contribution of UBN indicators $(0,1$, or 2$)$ and context (urban or rural) to performance on EF and intelligence tasks, we performed multiple linear regressions (Enter method) for continuous variables (attention, inhibitory control, working memory, intelligence, and learning) and an ordinal multiple regression for the ordinal variable (flexibility). We verified assumptions for 
TABLE 3 | Descriptive statistic of the nominal variables obtained from parents' interviews in urban and rural contexts.

\begin{tabular}{|c|c|c|c|c|c|}
\hline \multirow[b]{2}{*}{ Nominal variables } & \multicolumn{3}{|c|}{ Urban } & \multicolumn{2}{|c|}{ Rural } \\
\hline & Values & Frequency & Valid percentage & Frequency & Valid percentage \\
\hline \multirow[t]{2}{*}{ Gender } & Girls & 37 & 44.6 & 26 & 54.2 \\
\hline & Boys & 46 & 55.4 & 22 & 44.6 \\
\hline \multirow[t]{3}{*}{ Parenting } & Father and mother & 62 & 74.7 & 40 & 83.3 \\
\hline & Mother & 15 & 18.1 & 6 & 12.5 \\
\hline & Others & 6 & 7.2 & 2 & 4.2 \\
\hline \multirow[t]{2}{*}{ Low birth weight } & No & 66 & 91.7 & 32 & 88.9 \\
\hline & Yes & 6 & 8.3 & 4 & 11.1 \\
\hline \multirow[t]{2}{*}{ Preterm birth } & No & 68 & 75 & 36 & 81.8 \\
\hline & Yes & 8 & 16.7 & 8 & 18.2 \\
\hline \multirow[t]{2}{*}{ Potential central nervous system conditions } & No & 56 & 72.7 & 33 & 70.2 \\
\hline & Yes & 21 & 27.3 & 14 & 29.8 \\
\hline \multirow[t]{2}{*}{ Incubator } & No & 68 & 89.5 & 40 & 87 \\
\hline & Yes & 8 & 10.5 & 6 & 13 \\
\hline \multirow[t]{2}{*}{ Hospital internship } & No & 61 & 73.5 & 33 & 68.8 \\
\hline & Yes & 16 & 19.3 & 15 & 31.3 \\
\hline
\end{tabular}

linear (we conducted residual analyses to check normality, independence, homoscedasticity, and no collinearity) and for ordinal regressions (Pearson $\chi^{2}$ test to analyze goodness of fit and likelihood-ratio test of proportionality of odds to evaluate the proportional odds assumption). Context, UBN indicators, as well as the interaction between both, were included as independent variables.

In the second step, to determine which variables explained the effects on cognitive performance previously identified, we performed one two-way ANOVA for each of the 35 individual and environmental variables, including context and UBN indicators as factors. In the ANOVAs, to assure that differences were not generated by a non-homogenous UBN indicators distribution across both contexts, we added a non-parametric control of results through a permutation test (as was proposed by Maris and Oostenveld, 2007, p. 177). Furthermore, because of the high number of comparisons, we applied a Bonferroni correction to minimize potential error. For nominal variables (e.g., gender), we performed Kruskal Wallis tests. We selected the variables that only showed significant differences by context, i.e. variables that vary between rural and urban areas. We conducted correlations among those variables. In case of high correlation $(r>0.70)$, we selected one of them for the following analysis.

In the third step, to determine whether these selected variables were associated with EF and intelligence, we performed multiple linear/ordinal regressions (Enter method). In this model we included the selected variables (that differed between rural and urban contexts) as independent variables and one cognitive variable as the dependent variable. This model was applied to each of the six EF and intelligence variables.

\section{RESULTS}

Table 2 shows that, although the rural sample have, on average, higher scores on demographic characteristics linked to poverty (i.e., higher number of dependents in the household, lower father's and mother's completed level of education, lower father's and mother's occupation score, lower dwelling score and higher number of government subsides), some factors found in prior literature to be associated with children's better cognitive functioning (Bradley et al., 2001, p. 1844), scored higher among the rural than the urban sample (i.e., number of books at home, frequency of reading newspapers, frequency of listening to the radio and frequency of using cellphones).

The number of UBN indicators was larger in the rural (mean $=1.35, S D=0.76)$ than in the urban sample $($ mean $=0.36$, $S D=0.65)$ indicating that SES was lower in the rural context (descriptive statistics is in Tables 2-4; Pearson's $r=-0.57$ ). However, critical to the objectives of this paper, context and SES showed enough within variability and overlapped across urban and rural groups, to allow disentangling their contribution in multiple linear regressions (see model fitting information in Table 5). We then calculated multiple linear regressions with $\mathrm{UBN}$, context and the interaction as main factors (Figure $\mathbf{1}$ and Table 6), for all cognitive tasks except for Flexibility (ordinal variable). For Flexibility we calculated an ordinal regression, which showed an adequate goodness of fit [Pearson $\left.\chi^{2}(12)=13.433 ; p=0.338\right]$ and met the proportional odds assumption $\left[\chi^{2}(4)=6.63 ; p=0.156\right]$. Figure 1 reveals a general trend observed in the data across all cognitive measures: (1) cognitive performance decreases with UBN indicators and (2) for fixed values of UBN, performance is worse for the rural than for the urban context. Quantitative analyses of the multiple regressions showed that the effect of context accounted much more significantly and reliably for the variance of the data than the effect of UBN indicators. Context modulated Inhibitory Control, Working Memory and Intelligence. And also showed a marginally significant ( $p=0.051$ ) effect on learning. The effect of context was always in the same direction: urban scores are higher than rural scores (Table 5). Instead, while all the slopes $(\beta)$ of cognitive function as a function of UBN numbers were negative, 
TABLE 4 | Descriptive statistics of cognitive variables by context and UBN indicators.

\begin{tabular}{|c|c|c|c|c|c|c|}
\hline & \multicolumn{6}{|c|}{ Context } \\
\hline & \multicolumn{3}{|c|}{ Rural } & \multicolumn{3}{|c|}{ Urban } \\
\hline & $n$ & Mean & $S D$ & $n$ & Mean & $S D$ \\
\hline Attention & 41 & 5.34 & 3.60 & 79 & 7.11 & 3.88 \\
\hline Inhibitory control & 43 & 5.72 & 3.34 & 83 & 7.90 & 2.69 \\
\hline Working memory & 38 & 2.21 & 1.19 & 77 & 3.39 & 1.18 \\
\hline Intelligence & 27 & 1.85 & 2.21 & 72 & 5.13 & 2.08 \\
\hline Learning & 44 & 14.05 & 9.54 & 82 & 20.87 & 9.79 \\
\hline Flexibility & & Frequencies & Percentage & & Frequencies & Percentage \\
\hline No switch & & 19 & 43.18 & & 14 & 17.50 \\
\hline 0-3 switches & & 1 & 2.27 & & 6 & 7.50 \\
\hline 4-5 switches & & 8 & 18.18 & & 5 & 6.25 \\
\hline 6 switches & & 16 & 36.36 & & 55 & 68.75 \\
\hline
\end{tabular}

TABLE 5 | Results of multiple linear regressions for each cognitive variable.

\begin{tabular}{|c|c|c|c|c|c|c|c|c|}
\hline \multirow[b]{2}{*}{ Dependent variables } & \multirow[b]{2}{*}{$n$} & \multirow[b]{2}{*}{ df } & \multirow[b]{2}{*}{$\mathbf{F}$} & \multirow[b]{2}{*}{$R^{2}$} & \multicolumn{2}{|c|}{ Context } & \multicolumn{2}{|c|}{ UBN indicators } \\
\hline & & & & & Standard $\beta$ & $p$ & Standard $\beta$ & $p$ \\
\hline Attention & 120 & 2,119 & 3.10 & 0.050 & 0.187 & 0.080 & -0.060 & 0.573 \\
\hline Inhibitory control & 126 & 2,125 & 8.08 & 0.116 & 0.299 & 0.004 & -0.068 & 0.506 \\
\hline Working memory & 115 & 2,114 & 13.60 & 0.195 & 0.359 & 0.000 & -0.133 & 0.181 \\
\hline Intelligence & 99 & 2,98 & 23.96 & 0.333 & 0.538 & 0.000 & -0.085 & 0.349 \\
\hline \multirow[t]{2}{*}{ Learning } & 126 & 2,125 & 9.63 & 0.135 & 0.199 & 0.051 & -0.218 & 0.032 \\
\hline & & & $x^{2}$ & $R^{2}$ & Coefficient & $p$ & Coefficient & $p$ \\
\hline Flexibility & 124 & 2,123 & 22.86 & 0.083 & 0.075 & 0.454 & -0.801 & 0.002 \\
\hline
\end{tabular}

this effect was significant only for Flexibility and Learning. No significant effect of the interaction was found.

Once results suggested a major effect of context on cognitive performance, the following question emerged. Which individual and environmental aspects most prevalent in rural than in urban life posit greater risks for cognitive development? Our experimental study was well suited for this analysis, because we measured a wide distribution of 35 elements (including child health history, child temperament, home stimulation and sociodemographic variables, see variables in Tables 2, 3) that may be relevant to cognitive development in both populations.

To pursue this objective, we first identified which of the 35 variables differed by context and not by UBN. We performed two-way ANOVA for each of the 35 individual and environmental variables, including context and UBN indicators as factors. Variables that showed significant differences by context (but not by SES) were considered as candidates to inquire why rural context has such a stronger effect (for fixed UBN) compared to urban context. Significant results of ANOVAs, after Bonferroni correction, are informed in Table 6. Those analyses revealed that the following set of variables distinguished rural from urban populations: number of siblings, birth order (i.e., whether the child was first born, second born or so on), number of dependents in the household, father's completed level of education, father's occupation (i.e., whether the father is unemployed, construction worker, $\mathrm{CEO}$, etc.), number of government subsidies and past preschool attendance (in months). As it is shown in Tables 2, 6, number of siblings, birth order, number of dependents in the household and number of government subsidies are significantly higher in the rural sample, while father's completed level of education, father's occupation and past preschool attendance are significantly higher in the urban sample.

Later, we conducted Pearson correlations between those variables and we found that number of siblings correlated with birth order $(r=0.83 ; p<0.001)$. Therefore, we selected birth order for the following analysis.

Once this set of variables that differ between urban and rural contexts was identified we submitted it to multiple linear regressions to determine their predictive effect for each cognitive process. Regressions were conducted in rural and urban samples. Results showed that three of these variables had a significant effect on children cognitive performance (Figure 2): past preschool attendance, father's completed level of education, and number of government subsidies. Months of past preschool attendance was positively correlated with Attention $\left(R^{2}=0.193, F=3.678\right.$, $\beta=0.285, p=0.026)$. Importantly, as Figure 2 shows, when months of past preschool attendance is matched, children in both contexts showed similar cognitive performance. Also, father's completed level of education was correlated positively with Flexibility $\left(R^{2}=0.109, Z=3.24, \beta=0.265, p=0.001\right)$. Finally, 

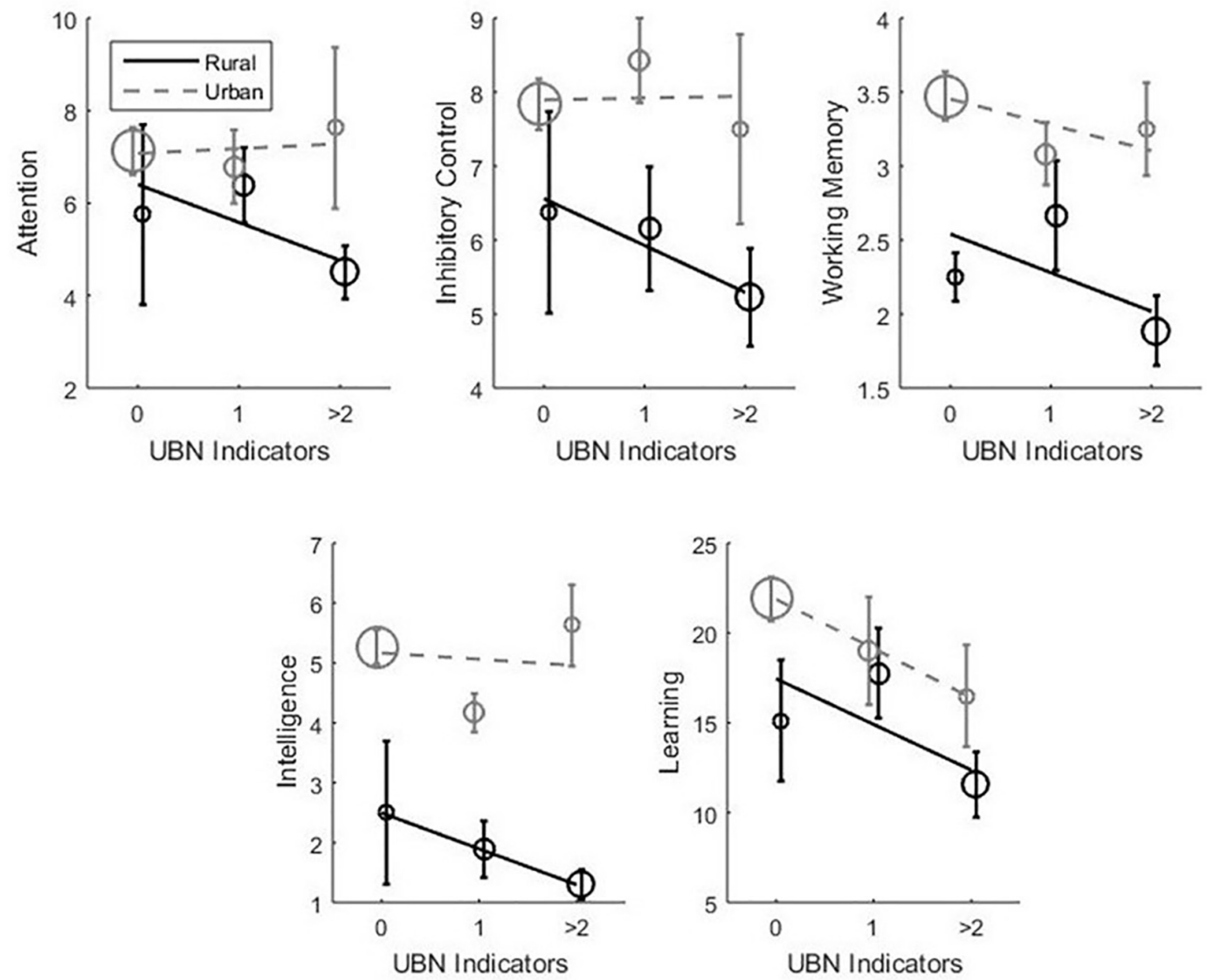

FIGURE 1 | Cognitive achievement as a function of context (urban or rural) and SES (measured as the number of UBN indicators). Lines correspond to linear fits of each context separately; points' sizes correspond to subsample sizes. Effects of UBN on flexibility are not shown in the figure because it is an ordinal variable.

TABLE 6 | Significant results of ANOVAs: environmental and individual variables that differ by context.

\begin{tabular}{|c|c|c|c|c|}
\hline & $\boldsymbol{F}$ & $p$ & Non parametric control $p$-value & $\eta^{2}$ \\
\hline Number of siblings & 20.151 & 0.000 & 0.000 & 0.178 \\
\hline Birth order & 21.517 & 0.000 & 0.000 & 0.177 \\
\hline Number of dependents in the household & 12.258 & 0.001 & 0.000 & 0.107 \\
\hline Father's completed level of education & 46.741 & 0.000 & 0.000 & 0.314 \\
\hline Father's occupation & 24.377 & 0.000 & 0.000 & 0.165 \\
\hline Number of government subsidies & 13.334 & 0.000 & 0.000 & 0.099 \\
\hline Past preschool attendance & 50.798 & 0.000 & 0.000 & 0.311 \\
\hline
\end{tabular}

having more government subsidies was negatively associated with Working memory $\left(R^{2}=0.200, F=3.670, \beta=-0.237, p=0.046\right)$.

\section{DISCUSSION}

A large number of studies (Brooks-Gunn and Duncan, 1997, p. 55; Bradley and Corwyn, 2002, p. 371; Hackman and Farah, 2009, p. 65) have shown that growing in low SES conditions may present a significant risk for cognitive development. Here we show that within this general trend, for fixed levels of UBN, performance in a broad variety of cognitive measures, is worse for children living in rural compared to urban settings. Hence, following the model of risk accumulation proposed by Evans (2003, p. 924), to live in a poor place that also belongs to a rural area would imply even a greater risk.

This results are particularly relevant, since the incidence of extreme poverty is higher in rural areas and in children populations (Olinto et al., 2013, p. 125). Previous studies on children's cognitive development in rural contexts have shown somehow non-linear results (Nadel and Sagawa, 2002, pp. 1105; Wells and Evans, 2003, p. 311; Foulkes and Mori, 2009, p. 83; Kandawasvika et al., 2012, p. 1; Miller and Votruba-Drzal, 2013, p. 234; Miller et al., 2013, p. 234; Förster and RojasBarahona, 2014, p. 476; Mykerezi et al., 2014, p. 17; Tine, 2014, 599; Castro and Rolleston, 2015, pp. 5-48; Gouin et al., 2015, p. 1) 

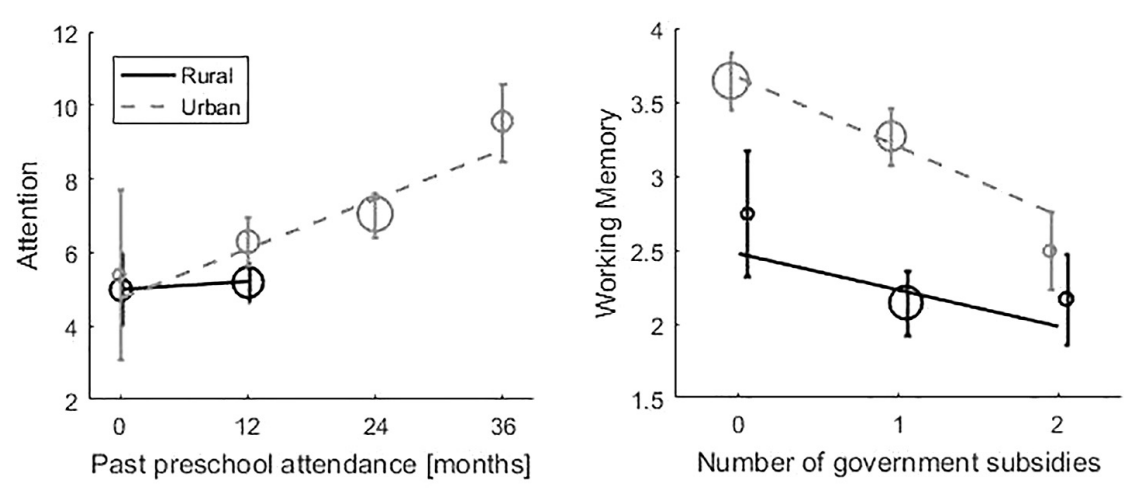

FIGURE 2 | Cognitive achievement dependence with months of past preschool attendance and number of government subsidies. Lines correspond to linear fits of each context separately; points' sizes correspond to subsample sizes. Rural scarceness is characterized by low past preschool attendance, high number of government subsidies and lower father's completed level of education. Effects of Father's completed level of education on flexibility are not shown in the figure because it is an ordinal variable.

and a meta analysis is very difficult to be performed because these studies are based on different cognitive measures, have used different age samples and, perhaps more importantly, have used different criteria to define rural contexts (Hart et al., 2005, p. 1149). In this controversial scenery, we provided a direct comparison between selected samples from different contexts, matched by age and for a wide spectrum of cognitive measures with overlapped distributions of UBN, albeit poverty was more pronounced in the rural sample. Although our sample size is small and each rural context has its own characteristics, it allowed us to factor out the distinct effects of context and poverty, and show that growing up in a rural setting (as the one of our sample) carries a higher risk for cognitive development.

Our study identified specifically two measures of scarceness that are more frequent in rural poverty and are decisive for cognitive function at a young age: lower past preschool attendance and lower father's completed level of education. We discuss below the relevance of these measures. Here we stress an implication of this finding: rearing context does not impact cognition per se, but it does so through the lack of opportunities available in one context compared to the other. In fact, as it is shown in Figure 2, when months of past preschool attendance is matched, children in both contexts showed similar cognitive performance. Conversely, when cognitive performance was compared across contexts (Figure 1), for fixed number of UBN children in rural context showed worse performance. This indicates that attempting to collapse poverty in a single numerical indicator (as UBN) might be misleading, because different contexts pose distinct and singular risks to cognitive development (Lipina, 2016, p. 241; Duncan et al., 2017, p. 413).

In sum, the study shows that poverty in rural setting affects child cognitive performance more than urban poverty. These findings highlight the importance of using methodological designs that do not confound the effects of context and SES, though they might be correlated. Poverty in rural and urban contexts stands for qualitatively and quantifiable different forms of scarceness. These differences showed not only that rural poverty is more extreme than urban poverty, but also that it is more risky for child cognitive development. Importantly, this risk is not captured by typical poverty measures (SES, UBN) (Lipina et al., 2011, pp. 8-17; Lipina, 2016, p. 241; Duncan et al., 2017, p. 413). In turn, this questions the relevance and generalizability of interventions to promote child development based on studies performed in urban samples, which is the case for the majority of the research in the field (Schreuder, 2010, p. 45). Our results suggest that interventions could have different effects in rural and urban settings. Also, an intervention that works in one rural context may not work in another rural context. More studies are needed in rural contexts to have a big quantum of information available to design interventions specifically for rural children.

The fact that the months of past preschool attendance was found as one of the two decisive factors (within a broad list of 35 indicators) is quite revealing. The time spent in preschool had a very strong effect on attentional performance (ranging from 5 points to 10 points); an increment of 1 month in past preschool attendance is associated with an increase in target identification (i.e., 0.323 more targets identified) in 30-s task. At the same time, the graph shows that this form of scarceness is much more prominent in the rural environment (there were no children with more than 12 months of past preschool attendance in the rural sample). This finding resonates and is in line with a long tradition of investigation that has shown that the first years of education have an enormous impact on future cognitive development (Campbell et al., 2002, p. 42; Magnuson et al., 2004, p. 115; Temple and Reynolds, 2007, p. 126; Barnett, 2008, pp. 137; Pianta et al., 2009, p. 49; Heckman, 2011, p. 31; Brinkman et al., 2017, p. 483).

In this regard, various studies have documented the negative association between cost and preschool attendance. Results of studies with samples from Mexico City (Wong and Levine, 1992, pp. 89-102), Brazil (Connelly et al., 1996, pp. 619-656), Kenya (Lokshin et al., 2004, pp. 240-276), and Romania (Lokshin and Fong, 2006) suggest that financial constraints play key roles in families' decisions about preschool attendance in developing countries. Conversely, our results showed that preschool attendance varied by context, but not by SES. A possible explanation for this result could be the lower number of preschool schools in rural contexts compared to urban ones 
(Gong et al., 2015, pp. 194-208). In the particular case of Argentina, evidence suggest that one of the main reasons of the urban-rural gap in preschool attendance is the lack of local preschool availability (Ferro, 2008, pp. 1-27) as it was also been reported in worldwide studies (Fuller et al., 2004, pp. 337-358; Bassok et al., 2011, pp. 7-19). However, due to other potential confounds (e.g., cultural factors) that we have not analyzed here, this hypothesis should be confirmed in future studies.

Our results encourage public policies oriented at maximizing access to preschool education in those contexts (Jiang et al., 2014, pp. 65-68), more so considering that in addition this may be protective from the impact of household deficits on cognitive development (Berry et al., 2016, p. 115).

The father's completed level of education also explained why cognitive performance was lower for children in rural than that of children in urban settings. Regarding previous literature this result has both, a consistent and novel aspect. It is consistent with studies that associate parental education with cognitive development (Ardila et al., 2005, 539; Grantham-McGregor et al., 2007, p. 60; Bibok et al., 2009, p. 17). Rural parents in our sample have, in average, one less completed educational level than urban parents (Table 2), which is in line with previous studies showing lower parental education in rural settings, as well as lower educational opportunities (Nadel and Sagawa, 2002, pp. 1105; Foulkes et al., 2008, p. 129; Foulkes and Mori, 2009, p. 83; Mykerezi et al., 2014, p. 17; Tine, 2017, pp. 9-22). Labor at early age (which has been shown to be a strong predictor of school drop-out), as well as distance and major costs of going to school, could explain why father's level of education in rural contexts, is lower than in urban settings (Bedi and Marshall, 1999, pp. 657682). In turn, low educational level is associated with early need of dropping out due to labor and with retention (Psacharopoulos, 1997, pp. 377-386; Bridgeland et al., 2006, pp. 1-44; Behrman et al., 2017, pp. 657-697). It is likely that this circle of scarceness, is more frequent in rural than in urban low SES contexts.

However, most studies in child development emphasized maternal over paternal education (Walker et al., 2007, p. 145). Little research is found regarding fathering and EF. Our result is novel because father's education explains better rural and urban differences on child development than that of the mother's (mother's completed educational level varied according context and SES). Therefore, although father education has not been studied extensively, our research suggests that this variable is a candidate to explain the rural-urban gap in EF.

The third variable to explain why cognitive performance was worse for children in rural than urban settings, was number of government subsidies. The pathways though which subsidies impact child cognitive development are still unclear, and might be multiple and non-linear. For instance, the type of subsidy (Baird et al., 2014, pp. 1-43), amount of cash (Bourguignon et al., 2003, pp. 229-254; Havnes and Mogstad, 2011, pp. 97-129), and recipient of the subsidy (Das, 2005, pp. 57-80) can influence that association. Besides this complex scenario, it is well established that government subsidies contribute to better cognitive achievement worldwide (Heckman, 2006, p. 1900) and this result has been demonstrated specifically in the case of Argentina (Roca, 2008, pp. 315-330; Agis et al., 2013, pp. 1-77). Therefore, the fact that number of subsidies was negatively associated with working memory, may seem paradoxical. However, it can be understood since government subsidies are a proxy measure of the precariousness of living conditions (it is given only to families with unemployed parents living in vulnerable living conditions). Hence, homes that receive more government subsidies are also homes that have the most vulnerable living conditions (Roca, 2011, pp. 30-43), in our study, the rural sample. This indicates that while government subsidies are effective (Roca, 2008, pp. 315-330; Roca, 2011, pp. 30-43; Agis et al., 2013, 1-77), their effect measured in variability in cognitive performance is insufficient to compensate -in Argentina- the original differences in income and social resources between urban and rural settings. Future studies should analyze under which conditions subsidies are more effective in urban or rural contexts and which are the specific characteristics a government subsidy has to have in order to bridge the urban-rural gap in child cognitive achievement.

In summary, the factorial study of dimensions of poverty we performed confirms that living in a rural area does not limit cognitive opportunities per se. Instead, certain forms of low SES that are typical of rural areas have a strong impact in cognitive development. This might explain the contradictory results of previous studies on the impact of living context on cognition (Wells and Evans, 2003, p. 311; Grace et al., 2006, pp. 1-28; McGrail and Humphreys, 2009, p. 124; Kandawasvika et al., 2012, p. 1; Förster and Rojas-Barahona, 2014, p. 476; Mykerezi et al., 2014, p. 17; Tine, 2014, p. 599; Castro and Rolleston, 2015, pp. 5-48; Gouin et al., 2015, p. 1). Here we measured the impact of living context on cognition trough standardized non-verbal intelligence scores as well as EF scores. Considering that EF are strong predictors of future cognitive development and wellbeing (McClelland, 1973, p. 1; Brooks-Gunn and Duncan, 1997, p. 55; Blair and Diamond, 2008, p. 899), our findings suggest that this scenario of lower achievements for children living in a low SES rural context is likely to condition their future lives, if no intervention mediates that path. Moreover, the effect of government subsidies-which in Argentina over the last few years have improved the quality of life of vulnerable families (Roca, 2008, pp. 315-330; Roca, 2011, pp. 30-43; Agis et al., 2013, pp. 1-77) - is insufficient to overcome these risks.

While more studies are required, our findings and many others (Slavin, 2002, p. 15; Yoshikawa et al., 2012, p. 272; Richter et al., 2017, p. 103) suggest that investment in early education may be a shield for a healthy cognitive development that stretches into adulthood. Regarding this issue, our results (Table 2) highlight some factors present in rural context, that, given the constraints in rural settings, might be facilitators for interventions. For example, the higher frequency of using cellphones, listening to the radio and reading newspapers, might be used to the transmission of early development tips to mothers, or to the presentation of cognitive training activities directly to children. Some interventions have showed promising results with similar methods (Gruver et al., 2016, p. 159; Nieuwboer et al., 2017, p. 61).

It is important to emphasize that while here we have studied typical urban and rural contexts in South America, the social 
and demographic characteristics of these contexts may vary in different regions of the planet. Also, our study is based on a middle size sample and has the limitation of not having ruralurban continuum, so we cannot draw conclusions regarding the intermediate contexts such as suburbs or small towns (Foulkes and Mori, 2009, p. 83). Hence, the conclusions of this study have to be understood relative to this particular region of the world. Nevertheless, our study raises a general concern about studies of low SES and cognition by signaling that poverty scores may provide insufficient and erroneous characterizations of a population. Instead, understanding what dimensions of scarceness characterize a population might open a wider window for our understanding of the adequacy of educational and governmental interventions that target the prevention of deficits in cognitive development.

\section{CONCLUSION}

As poverty is more extreme in rural settings, the effects of context (rural/urban) and socioeconomic status (SES) are often confounded. In this paper we isolated these effects and showed that living in a non-urban context has a negative impact on children's cognitive performance that is independent of SES and more pronounced than that of low SES. Poverty in rural and urban contexts imply qualitatively and quantifiable different forms of scarceness. Factors including fewer months of past preschool attendance as well as a lower completed level of education of fathers, typical of rural contexts, explained that, for the same level of SES, children in rural settings performed consistently worse than children in urban settings. These results have implications for the design of public policy and intervention programs that aim to address the needs of specific living contexts and socioeconomic groups.

\section{DATA AVAILABILITY STATEMENT}

The datasets generated and analyzed for this study can be found in the PsyArxiv https://mfr.osf.io/render?url=https://osf. io $/ 65 z 2 y /$ ?action $=$ download $\% 26$ mode $=$ render.

\section{REFERENCES}

Agis, E., Cañete, C., and Panigo, D. (2013). El impacto de la asignación universal por hijo en Argentina. Empleo Desempleo Polít. Empleo 15, $1-77$.

Ardila, A., Rosselli, M., Matute, E., and Guajardo, S. (2005). The influence of the parents' educational level on the development of executive functions. Dev. Neuropsychol. 28, 539-560. doi: 10.1207/s15326942dn 2801_5

Baird, S., Ferreira, F. H., Özler, B., and Woolcock, M. (2014). Conditional, unconditional and everything in between: a systematic review of the effects of cash transfer programmes on schooling outcomes. J. Dev. Effect. 6, 1-43. doi: 10.1080/19439342.2014.890362

Barnett, W. S. (2008). Preschool Education and its Lasting Effects: Research and Policy Implications", Boulder and Tempe: Education and the Public Interest Center and Education Policy Research Unit. Available at: https://nepc.colorado. edu/sites/default/files/PB-Barnett-EARLY-ED_FINAL.pdf

\section{ETHICS STATEMENT}

This study was carried out in accordance with the recommendations of APA's ethical standards. All subjects gave written informed consent in accordance with the Declaration of Helsinki. The protocol was approved by the Ethical Committee of the Centro de Educación Médica e Investigaciones Clínicas "Norberto Quirno".

\section{AUTHOR CONTRIBUTIONS}

$\mathrm{MH}, \mathrm{MSS}, \mathrm{AG}, \mathrm{SL}$, and MS designed the experiments. $\mathrm{MH}$ collected the data. MA contributed in the logistic organization for the fieldwork in the rural setting. MH, DS, MSS, SL, and MS worked in the data analysis and interpretation. $\mathrm{MH}$ and MS wrote the manuscript. All co-authors revised and contributed to manuscript revision, read and approved the submitted version.

\section{FUNDING}

This work was supported by Fundación Mundo Sano and Corporación Andina de Fomento. MS is sponsored by the James McDonnell Foundation 21st Century Science Initiative in Understanding Human Cognition-Scholar Award. Funding sources had no involvement in study design, in the collection, analysis and interpretation of data, in the writing of the report, or in the decision to submit the article for publication.

\section{ACKNOWLEDGMENTS}

The authors thank to Ministries of Education of Santiago del Estero, and of City of Buenos Aires, to Verónica Ramenzoni, Bibiana Carpinella and to the school community from Schools JIN B and JIN C (District XIII), 'El Chañarcito' and 'Mi Pequeño Pony.'

Bassok, D., Fitzpatrick, M., and Loeb, S. (2011). Disparities in Child Care Availability Across Communities: Differential Reflection of Targeted Interventions and Local Demand (Working paper, Center for Education Policy Analysis). Stanford, CA: Stanford University.

Bedi, A. S., and Marshall, J. H. (1999). School attendance and student achievement: evidence from rural Honduras. Econ. Dev. Cult. Change 47, 657-682. doi: 10. $1086 / 452423$

Behrman, J. R., Schott, W., Mani, S., Crookston, B. T., Dearden, K., Duc, L. T., et al. (2017). Intergenerational transmission of poverty and inequality: parental resources and schooling attainment and children's human capital in Ethiopia, India, Peru, and Vietnam. Econ. Dev. Cult. Change 65, 657-697. doi: 10.1086/ 691971

Berry, D., Blair, C., Willoughby, M., Garrett-Peters, P., Vernon-Feagans, L., Mills-Koonce, W. R., et al. (2016). Household chaos and children's cognitive and socio-emotional development in early childhood: Does childcare play a buffering role? Early Child Res. Q. 34, 115-127. doi: 10.1016/j.ecresq.2015. 09.003 
Bibok, M. B., Carpendale, J. I., and Müller, U. (2009). Parental scaffolding and the development of executive function. New Dir. Child Adolesc. Dev. 123, 17-34. doi: $10.1002 / \mathrm{cd} .233$

Bierman, K. L., Domitrovich, C. E., Nix, R. L., Gest, S. D., Welsh, J. A., Greenberg, M. T., et al. (2008). Promoting academic and social-emotional school readiness: the head start redi program. Child Dev. 79, 1802-1817. doi: 10.1111/j.14678624.2008.01227.x

Blair, C., and Diamond, A. (2008). Biological processes in prevention and intervention: the promotion of self-regulation as a means of preventing school failure. Dev. Psychopathol. 20, 899-911. doi: 10.1017/S09545794080 00436

Bourguignon, F., Ferreira, F. H., and Leite, P. G. (2003). Conditional cash transfers, schooling, and child labor: micro-simulating Brazil's Bolsa Escola program. World Bank Econ. Rev. 17, 229-254. doi: 10.1093/wber/lhg018

Bradley, R. H., and Corwyn, R. F. (2002). Socioeconomic status and child development. Annu. Rev. Psychol. 53, 371-399. doi: 10.1146/annurev.psych.53. 100901.135233

Bradley, R. H., Corwyn, R. F., McAdoo, H. P., and GarcíaColl, C. (2001). The home environments of children in the United States part I: variations by age, ethnicity, and poverty status. Child Dev. 72, 1844-1867. doi: 10.1111/1467-8624.t01-100382

Bridgeland, J. M., DiIulio, J. J. Jr., and Morison, K. B. (2006). The Silent Epidemic: Perspectives of High School Dropouts. Washington, DC: Civic Enterprise, 1-44.

Brinkman, S. A., Hasan, A., Jung, H., Kinnell, A., Nakajima, N., and Pradhan, M. (2017). The role of preschool quality in promoting child development: evidence from rural Indonesia. EECERJ 25, 483-505. doi: 10.1080/1350293X.2017. 1331062

Brody, G. H., Murry, V. M., Kim, S., and Brown, A. C. (2002). longitudinal pathways to competence and psychological adjustment among African American children living in rural single-parent households. Child Dev. 73, 1505-1516. doi: 10.1111/1467-8624.00486

Brooks-Gunn, J., and Duncan, G. J. (1997). The effects of poverty on children. Future Child 7, 55-71. doi: 10.2307/1602387

Brown, L., Sherbenou, R. J., and Johnsen, S. K. (2010). Toni-4, Test of Nonverbal Intelligence. Texas: Pro-Ed, 625.

Burchinal, M., Vernon-Feagans, L., Cox, M., and Key Family Life Project Investigators. (2008). Cumulative social risk, parenting, and infant development in rural low-income communities. Parent Sci. Pract. 8, 41-69. doi: 10.1080/ 15295190701830672

Campbell, F. A., Ramey, C. T., Pungello, E., Sparling, J., and Miller-Johnson, S. (2002). Early childhood education: young adult outcomes from the abecedarian project. Appl. Dev. Sci. 6, 42-57. doi: 10.1037/a0026644

Castro, J. F., and Rolleston, C. (2015). Explaining the Urban-Rural Gap in Cognitive Achievement in Peru: The Role of Early Childhood Environments and School Influences. Young Lives Working Paper 139. London: University of Oxford.

Cohen, J., Cohen, P., West, S. G., and Aiken, L. S. (2013). Applied Multiple Regression/ Correlation Analysis for the Behavioral Sciences. Abingdon: Routledge, 736. doi: 10.4324/9780203774441

Colombo, J. A., and Lipina, S. (2005). Hacia un programa público de estimulación cognitiva infantil: Fundamentos, métodos y resultados de una experiencia de intervención preescolar controlada. Buenos Aires: Paidós, 174.

Connelly, R., DeGraff, D. S., and Levison, D. (1996). Women's employment and child care in Brazil. Econ. Dev. Cult. Change 44, 619-656. doi: 10.1086/452234

Das, J. (2005). Reassessing conditional cash transfer programs. World Bank Res. Observer 20, 57-80. doi: 10.1093/wbro/lki005

Duncan, G. J., Magnuson, K., and Votruba-Drzal, E. (2017). Moving beyond correlations in assessing the consequences of poverty. Annu. Rev. Psychol. 68, 413-434. doi: 10.1146/annurev-psych-010416-044224

Evans, G. W. (2003). A multimethodological analysis of cumulative risk and allostatic load among rural children. Dev. Psychol. 39, 924-933. doi: 10.1037/ 0012-1649.39.5.924

Ferro, L. A. (2008). Situación de la Educación Inicial en la Argentina y Perspectivas para su Universalización. Informes y Estudios sobre la Situación Educativa, 8. Availble at: https://www.ctera.org.ar/index.php/educacion/ investigacion/item/download/146_962de88afa322e95365fea28ad49e688

Förster, M. C. E., and Rojas-Barahona, C. A. (2014). Disadvantaged preschool children from rural areas: the importance of home practices and nursery attendance in the development of early literacy skills. Cult. Educ. 26, 476-504. doi: 10.1080/11356405.2014.973668

Foulkes, D. M., and Mori, E. S. (2009). Formación de la capacidad cognitiva en México: impactos económicos y de políticas públicas. Estud. Econ. 3, 83-122.

Foulkes, D. M., Olivo, M. F. L., and Mori, E. S. (2008). Habilidades cognitivas: transmisión intergeneracional por niveles socioeconómicos. Estud. Econ. 23, $129-156$.

Frye, D., Zelazo, P. D., and Palfai, T. (1995). Theory of mind and rule-based reasoning. Cogn. Dev. 10, 483-527. doi: 10.1016/0885-2014(95)90024- 1

Fuller, B., Loeb, S., Strath, A., and Carrol, A. B. (2004). States formation of the child care sector: family demand and policy action. Soc. Educ. 77, 337-358. doi: 10.1177/003804070407700404

Gerstadt, C. L., Hong, Y. J., and Diamond, A. (1994). The relationship between cognition and action: performance of children $312-7$ years old on a strooplike day-night test. Cognition 53, 129-153. doi: 10.1016/0010-0277(94)90 068-X

Gong, X., Xu, D., and Han, W. J. (2015). Household income and preschool attendance in China. Child Dev. 86, 194-208. doi: 10.1111/cdev.12294

Gouin, M., Flamant, C., Gascoin, G., Rouger, V., Florin, A., Guimard, P., et al. (2015). The association of urbanicity with cognitive development at five years of age in preterm children. PLoS One 10:e0131749. doi: 10.1371/journal.pone. 0131749

Grace, C., Shores, E. F., Zaslow, M., Brown, B., Aufseeser, D., and Bell, L. (2006). Rural Disparities in Baseline Data of the Early Childhood Longitudinal Study: A Chartbook. Missisipi: National Center for Rural Early Childhood Learning Initiatives, 28.

Grantham-McGregor, S., Cheung, Y. B., Cueto, S., Glewwe, P., Richter, L., and International Child Development Steering Group (2007). Developmental potential in the first 5 years for children in developing countries. Lancet 369 , 60-70. doi: 10.1016/S0140-6736(07)60032-4

Gruver, R. S., Bishop-Gilyard, C. T., Lieberman, A., Gerdes, M., Virudachalam, S., Suh, A. W., et al. (2016). A social media peer group intervention for mothers to prevent obesity and promote healthy growth from infancy: development and pilot trial. JMIR Res. Protoc. 5:e159. doi: 10.2196/resprot.5276

Hackman, D. A., and Farah, M. J. (2009). Socioeconomic status and the developing brain. Trends Cogn. Sci. 13, 65-73. doi: 10.1016/j.tics.2008.11.003

Hamilton, M. (1960). A rating scale for depression. J. Neurol. Neurosurg. Psychiatry 23, 56-62. doi: 10.1136/jnnp.23.1.56

Hart, L. G., Larson, E. H., and Lishner, D. M. (2005). Rural definitions for health policy and research. Am. J. Public Health 95, 1149-1155. doi: 10.2105/AJPH. 2004.042432

Havnes, T., and Mogstad, M. (2011). No child left behind: subsidized child care and children's long-run outcomes. Am. Econ. J. 3, 97-129. doi: 10.1257/pol.3.2.97

Heckman, J. J. (2006). Skill formation and the economics of investing in disadvantaged children. Science 312, 1900-1902. doi: 10.1126/science.1128898

Heckman, J. J. (2011). The economics of inequality: the value of early childhood education. Am. Educ. 35, 31-35.

Hermida, M. J. (2018). Base Total Añatuya 4.xls. PsyArxiv. Version 1. Available at: https://osf.io/3U2ET/

Horn, J. L., and Cattell, R. B. (1966). Refinement and test of the theory of fluid and crystallized general intelligences. J. Educ. Psychol. 57, 253-270. doi: 10.1037/ h0023816

Instituto Nacional de Estadísticas y Censos (2010). Anuario Estadístico de la República Argentina. Buenos Aires: INDEC, 96.

Jiang, W., Yang, H., and Xu, L. (2014). "The study of the development of urban and rural preschool education in justice-orientation," in 2014 International Conference on Education Reform And Modern Management (ermm-14) (Hong Kong: Atlantis Press), 65-68.

Kandawasvika, G. Q., Mapingure, P. M., Nhembe, M., Mtereredzi, R., and StrayPedersen, B. (2012). Validation of a culturally modified short form of the Mccarthy scales of children's abilities in 6 to 8 year old zimbabwean school children: a cross section study. BMC Neurol. 12:147. doi: 10.1186/1471-237712- 147

Lichter, D. T., and Johnson, K. M. (2007). The changing spatial concentration of America's rural poor population. Rural Soc. 72, 331-358. doi: 10.1526/ 003601107781799290 
Lipina, S. J. (2016). Critical considerations about the use of poverty measures in the study of cognitive development. Int. J. Psychol. 52, 241-250. doi: 10.1002/ijop. 12282

Lipina, S. J., Simonds, J., and Segretin, M. S. (2011). Recognizing the child in child poverty. Vulnerable Child. Youth Stud. 6, 8-17. doi: 10.1080/17450128.2010. 521598

Lokshin, M., and Fong, M. (2006). Women's labour force participation and child care in Romania. J. Dev. Stud. 42, 90-109. doi: 10.1080/00220380500356746

Lokshin, M., Glinskaya, E., and Garcia, M. (2004). The effect of early childhood development programs on women's labor force participation and older children's schooling in Kenya. J. Afr. Econ. 13, 240-276. doi: 10.1596/18139450-2376

Magnuson, K. A., Meyers, M. K., Ruhm, C. J., and Waldfogel, J. (2004). Inequality in preschool education and school readiness. Am. Educ. Res. J. 41, 115-157. doi: 10.3102/00028312041001115

Maris, E., and Oostenveld, R. (2007). Nonparametric statistical testing of eeg-and meg-data. J. Neurosci. Methods 164, 177-190. doi: 10.1016/j.jneumeth.2007. 03.024

McClelland, D. C. (1973). Testing for competence rather than for" intelligence. Am. Psychol. 28, 1-14. doi: 10.1037/h0034092

McGrail, M. R., and Humphreys, J. S. (2009). The index of rural access: an innovative integrated approach for measuring primary care access. BMC Health Serv. Res. 9:124. doi: 10.1186/1472-6963-9-124

Miller, P., and Votruba-Drzal, E. (2013). Early academic skills and childhood experiences across the urban-rural continuum. Early Child Res. Q. 28, 234-248. doi: 10.1016/j.ecresq.2012.12.005

Miller, P., Votruba-Drzal, E., and Setodji, C. M. (2013). Family income and early achievement across the urban-rural continuum. Dev. Psychol. 49, 1452-1465. doi: $10.1037 / \mathrm{a} 0030244$

Moffitt, T. E., Arseneault, L., Belsky, D., Dickson, N., Hancox, R. J., Harrington, H., et al. (2011). A gradient of childhood self-control predicts health, wealth, and public safety. Proc. Natl. Acad. Sci. U.S.A. 108, 2693-2698. doi: 10.1073/pnas. 1010076108

Morgan, K. E. (2015). The cognitive effects of chronic malnutrition and environment on working memory and executive function in children. Independent Study Project 2053, 1-42.

Mykerezi, E., Kostandini, G., Jordan, J. L., and Melo, I. (2014). On rural-urban differences in human capital formation: finding the 'bottlenecks'. J. Rural Soc. Sci. 29, 17-47.

Nadel, W., and Sagawa, S. (2002). America's Forgotten Children: Child Poverty in Rural America. Wesport: Save the children.

Nieuwboer, C. C., Fukkink, R. G., and Hermanns, J. (2017). Analysing empowerment-oriented email consultation for parents: development of the Guiding the Empowerment Process model. Child Fam. Soc. Work 22, 61-71. doi: $10.1111 / \mathrm{cfs} .12185$

Olinto, P., Beegle, K., Sobrado, C., and Uematsu, H. (2013). The state of the poor: Where are the poor, where is extreme poverty harder to end, and what is the current profile of the world's poor? Econ. Premise 125, 1-8.

Paxson, C., and Schady, N. (2007). Cognitive development among young children in Ecuador the roles of wealth, health, and parenting. J. Hum. Resour. 42, 49-84. doi: 10.3368/jhr.XLII.1.49

Pianta, R. C., Barnett, W. S., Burchinal, M., and Thornburg, K. R. (2009). The effects of preschool education what we know, how public policy is or is not aligned with the evidence base, and what we need to know. Psychol. Sci. Public Interest 10, 49-88. doi: 10.1177/1529100610381908

Portellano, J., Mateos, R., Martínez, R., Tapia, A., and Granados, M. (2000). Manual CUMANIN, Cuestionario de Madurez Neuropsicológica Infantil. Madrid: Tea Ediciones, 396.

Psacharopoulos, G. (1997). Child labor versus educational attainment Some evidence from Latin America. J. Population Econ. 10, 377-386. doi: 10.1007/ s001480050049

Putnam, S. P., and Rothbart, M. K. (2006). Development of short and very short forms of the children's behavior questionnaire. J. Pers. Assess. 87, 102-112. doi: 10.1207/s15327752jpa8701_09

Richter, L. M., Daelmans, B., Lombardi, J., Heymann, J., Boo, F. L., Behrman, J. R., et al. (2017). Investing in the foundation of sustainable development: pathways to scale up for early childhood development. Lancet $389,103-118$. doi: 10.1016/S0140-6736(16)31698-1

Robinson, L. R. (2017). Differences in health care, family, and community factors associated with mental, behavioral, and developmental disorders among children aged 2-8 years in rural and urban areas in the United States, 20112012. MMWR Surveill. Summ. 66, 1-11. doi: 10.15585/mmwr.ss6608a1

Roca, E. (2008). "Evolución de la cobertura de la seguridad social y su relación con el mercado de trabajo," in El Estado y reconfiguración de la Protección Social, eds M. Novick and Y. G. Pérez Sosto (Buenos Aires: Siglo XXI- Inst), 315-330.

Roca, E. (2011). Asignación universal por hijo (AUH): extensión de las asignaciones familiares. Rev. Debate Público 1, 29-43.

Schreuder, R. (2010). Unstacking the deck: rural poverty and the effects on childhood development. Michigan J. Soc. Work Soc. Welf. 1, 45-55.

Sigman, M., Peña, M., Goldin, A. P., and Ribeiro, S. (2014). Neuroscience and education: prime time to build the bridge. Nat. Neurosci. 17, 497-502. doi: $10.1038 / \mathrm{nn} .3672$

Slavin, R. E. (2002). Evidence-based education policies: transforming educational practice and research. Educ. Res. 31, 15-21. doi: 10.3102/0013189X031007015

Stokes, D. E. (2011). Pasteur's Quadrant: Basic Science and Technological Innovation. Washington DC: Brookings Institution Press, 196.

Tardif, T., So, C. W.-C., and Kaciroti, N. (2007). Language and false belief: evidence for general, not specific, effects in cantonese-speaking preschoolers. Dev. Psychol. 43, 318-340. doi: 10.1037/0012-1649.43.2.318

Temple, J. A., and Reynolds, A. J. (2007). Benefits and costs of investments in preschool education: evidence from the child-parent centers and related programs. Econ. Educ. Rev. 26, 126-144. doi: 10.1016/j.econedurev.2005.11.004

Tine, M. (2014). Working memory differences between children living in rural and urban poverty. J. Cogn. Dev. 15, 599-613. doi: 10.1080/15248372.2013.797906

Tine, M. (2017). "Growing up in Rural vs. Urban poverty: contextual, academic, and cognitive differences," in Poverty, Inequality and Policy, ed. G. Staicu (London: IntechOpen), 14. doi: 10.5772/intechopen.68581

Vernon-Feagans, L., and Cox, M. (2013). The family life project: an epidemiological and developmental study of young children living in poor rural communities: i. poverty, rurality, parenting, and risk: an introduction. Monogr. Soc. Res. Child Dev. 78, 1-23. doi: 10.1111/mono. 12047

Walker, S. P., Wachs, T. D., Gardner, J. M., Lozoff, B., Wasserman, G. A., Pollitt, E., et al. (2007). Child development: risk factors for adverse outcomes in developing countries. Lancet 369, 145-157. doi: 10.1016/S0140-6736(07)60076-2

Wechsler, D. (1991). Wisc-iii: Wechsler Intelligence Scale for Children: Manual. San Antonio, TX: Psychological Corporation, 412.

Wechsler, D. (2004). Wppsi-iii. Wechsler Preeschool and Primary Scale of Intelligence-Third Edition Manual. San Antonio, TX: The Psychological Corporation, 345.

Wells, N. M., and Evans, G. W. (2003). Nearby nature: a buffer of life stress among rural children. Environ. Behav. 35, 311-330. doi: 10.1177/0013916503251445

Wong, R., and Levine, R. (1992). The effect of household structure on women's economic activity and fertility: evidence from recent mothers in urban Mexico. Economic Dev. Cult. Change 41, 89-102. doi: 10.1086/451997

Yoshikawa, H., Aber, J. L., and Beardslee, W. R. (2012). The effects of poverty on the mental, emotional, and behavioral health of children and youth: implications for prevention. Am. Psychol. 67, 272-284. doi: 10.1037/a0028015

Zelazo, P. D. (2006). The dimensional change card sort (dccs): a method of assessing executive function in children. Nat. Protoc. 1, 297-301. doi: 10.1038/ nprot. 2006.46

Conflict of Interest Statement: The authors declare that the research was conducted in the absence of any commercial or financial relationships that could be construed as a potential conflict of interest.

Copyright (c) 2019 Hermida, Shalom, Segretin, Goldin, Abril, Lipina and Sigman. This is an open-access article distributed under the terms of the Creative Commons Attribution License (CC BY). The use, distribution or reproduction in other forums is permitted, provided the original author(s) and the copyright owner(s) are credited and that the original publication in this journal is cited, in accordance with accepted academic practice. No use, distribution or reproduction is permitted which does not comply with these terms. 